\title{
Effect of Posterior Tibial Slope on Postoperative Flexion and Functional Outcome in Total Knee Arthroplasty. A Double Blinded Randomised Controlled Trial
}

\author{
N Howard ${ }^{1}$, C Jakaraddi ${ }^{1}$, JR Fountain ${ }^{1}$, JA Pope ${ }^{1}$, JS Davidson ${ }^{1}$, D Patel ${ }^{1}$ and AJA Santini ${ }^{1,2 *}$ \\ ${ }^{1}$ The Lower Limb Unit, Department of Orthopaedics, Liverpool University Hospitals NHS Foundation Trust, England \\ ${ }^{2}$ Faculty of Life and health Sciences, The University of Liverpool, England
}

*Corresponding author: AJA Santini, Lower Limb Unit, Department of Orthopaedics, Broadgreen Hospital, Liverpool University Hospitals NHS Foundation Trust, Liverpool, England

\begin{abstract}
ARTICLE INFO
Received: 蔧 April 19, 2021

Published: May 04, 2021

Citation: N Howard, C Jakaraddi, JR Fountain, JA Pope, AJA Santini, et al., Effect of Posterior Tibial Slope on Postoperative Flexion and Functional Outcome in Total Knee Arthroplasty. A Double Blinded Randomised Controlled Trial. Biomed J Sci \& Tech Res 35(3)-2021. BJSTR. MS.ID.005719.
\end{abstract}

Keywords: Posterior Tibial Slope; Flexion Gap; Total Knee Arthroplasty; Cruciate-Retaining; Range of Motion

\section{ABSTRACT}

Background: A posterior tibial slope in total knee arthroplasty may improve femoral roll-back, providing more normal knee kinematics and increased flexion. Although the roll-back mechanism is complex and not fully replicated in modern arthroplasties, a posterior slope reduces the height of the posterior tibial wall. Hence contact between the posterior tibia and posterior femur occurs later in the range of flexion which should in theory maximize flexion. Clinical trials thus far have shown little difference between knee replacements using varying tibial slope values. However, most such trials have been retrospective case series.

Methods: A prospective double-blind trial randomised 241 patients undergoing a primary Profix knee replacement to either a $0^{\circ}$ or $4^{\circ}$ posterior tibial slope. The same specialist physiotherapist measured range of motion, Short Form-12 and Western Ontario and McMaster Universities Osteoarthritis Index (WOMAC) scores pre-operatively, then at 3 and 12 months post-operatively. Patients and the physiotherapist were blinded to the tibial slope angle.

Results: 241 patients were recruited, with 117 patients randomised to the $0^{\circ}$ group and 124 into the $4^{\circ}$ group. No significant difference in either range of movement or quality of life measurements were found at any time point between the $0^{\circ}$ and $4^{\circ}$ groups.

Conclusions: This in vivo study has shown no correlation with flexion or outcome scores between two posterior tibial slopes in a cruciate retaining arthroplasty. The clinical significance of the posterior tibial slope within a narrow therapeutic window may therefore be negligible.

\section{Introduction}

Total knee arthroplasty is a well-established treatment for degenerative knee conditions. It is one of the most successful and common surgeries with improvement in quality of life exceeded only by coronary artery bypass and total hip replacement [1]. Whilst the primary aim is to alleviate pain, improved implant design and survival have tried to improve functional outcome and quality of life [2]. Limited range of motion correlates negatively with post-operative function and patient satisfaction [3,4]. Activities of daily living require a minimum $90^{\circ}$ flexion, with increased levels of function such as swimming and cycling requiring an even greater range of flexion [5]. Inability to regain deep or maximal flexion is not an uncommon postoperative complaint. Numerous studies have been conducted evaluating various surgical and patient factors on post-operative range of movement with pre- 
operative range of movement being undeniably the most consistent predictor. The range of flexion ultimately achieved however is likely to be multifactorial and surgical factors including maintenance of posterior tibial slope, posterior condylar offset and alteration of the joint line, although contentious, may play a significant role [6,7]. Most modern knee arthroplasty systems allow posterior tibial slope options, typically zero, three, four some up to seven degrees. There is little consensus on the optimum tibial slope with surgeons using their 'preferred' cutting block to obtain the desired slope or attempt to recreate the preoperative physiological posterior tibial slope.

A posterior tibial slope may improve femoral roll-back, especially laterally, providing more 'normal' knee kinematics, leading to increased flexion. In a skeletal model, a posterior tibial slope reduces the height of the posterior tibial wall and hence delays contact between the posterior tibia and femur during flexion and theoretically leading to an increased range of movement. In vivo, however, the soft tissues may affect the flexion gained due to tissue impingement or even stiffness. An excessive posterior slope may lead to flexion instability, posterior wear, loss of full extension and early loosening of the tibial component [8]. The benefit of altering the tibial cutting angle therefore remains unclear. Numerous cadaveric studies have suggested that recreating the normal $5^{\circ}$ to $10^{\circ}$ tibial slope increases the flexion gap and improves post-operative range of movement $[9,10]$. However, many clinical trials have failed to replicate these results [11-14]. The studies comparing tibial slope angle with post-operative movement have been retrospective case series involving different implants with multiple variants. Because the flexion gap and therefore range of movement are influenced by many factors in addition to the tibial slope, including posterior cruciate ligament tension, femoral component size (posterior condylar offset) and quadriceps tightness, it is difficult to analyse the effect of the slope using retrospective case series. We therefore undertook a prospective double-blind randomised controlled trial comparing the posterior tibial slope angle with post-operative range of movement and functional outcome based on the null hypothesis that the tibial slope makes no difference to final movement at one year and that there is no difference in functional outcome between one group with a tibial slope cut at $0^{\circ}$ and another with a slope cut at $4^{\circ}$.

\section{Methods}

\section{Ethics}

Ethical approval was obtained before study start (Research Ethics Committee reference 05/Q1502/80). A National Health Service grant funded a research fellow (CAJ) to run the trial.

\section{Statistical Analysis}

Pre-trial calculation showed that detecting a mean $7.5^{\circ}$ difference in flexion between the two groups with $80 \%$ power required a sample size of 125 patients per arm. Statistical analysis was carried out using Stats Direct (www.statsdirect.co.uk). The Mann-Whitney $U$ test was used to test the null hypothesis, with $p<0.05$ as significant and all results reported with two-sided $p$ values.

\section{Patient Recruitment}

The trial recruited 256 consecutive patients under the care of the two senior surgeons (AJAS \& JSD) at the same institute. Six patients withdrew before surgery, leaving 250 who were consented and randomised. All patients had a cruciate-retaining Profix implant (Smith \& Nephew, Watford, UK). The standard protocol in our unit at the time of the trial was for patients under 70 years of age to have a zirconium/niobium alloy femoral component and an all-polyethylene tibial base. Patients over 70 years of age had variations in the prosthesis used. Hence to prevent differences being attributable to implant variation we limited the trial to patients aged 70 years or under. Pre-operatively, a specialist physiotherapist (JP) measured extension and flexion using a goniometer and assessed each patient using two validated patientreported outcome scoring systems: the Western Ontario and McMaster Universities Osteoarthritis Index (WOMAC), for pain, stiffness and physical outcome, and the Short Form-12 (SF-12), for health-related physical and mental wellbeing. In the WOMAC scoring system a lower score indicates a better outcome; in the SF12 scoring system a higher score indicates a better outcome.

\section{Surgical Techniques}

Patient randomisation to the $0^{\circ}$ or $4^{\circ}$ tibial slope group was relayed to the surgeon in the anesthetic room from a numbered sealed envelope by a pre-determined randomisation allocation. The operations were done through a standard trivector approach and the posterior cruciate ligament was retained as standard. The tibial resection was made as per Smith and Nephew operative technique recommendations using either the $0^{\circ}$ or $4^{\circ}$ cutting block. An intramedullary tibial alignment rod was inserted and securely fastened to the allocated tibial cutting block with a set screw and two supplementary pins were placed in the tibia. All cuts were made using an implant specific 'Profix' saw blade designed to minimize toggle and increase accuracy of the cuts. The standard poly-ethylene inserts used had no 'inbuilt' posterior slope, hence the slope cut on the tibia produced the final posterior slope. A 'Conforming Plus' insert with anterior lip was used if the surgeon felt the posterior cruciate ligament was non-functional $(n=7$ patients). All components were cemented using CMWII gentamicinenhanced cement (DePuy CMW, UK). All operations were carried out by the two senior authors or by trainees under their direct supervision as first assistant. All patients adhered to the standard hospital post-operative protocol. Cefuroxime was given on induction with subcutaneous dalteparin was started on the day of surgery and continued for ten days, along with thromboembolism- 
deterrent stockings. Patients were mobilised on the day or day after surgery. They were discharged home once independently mobile with at least 80 degrees of flexion and had standardised outpatient physiotherapy follow up.

\section{Outcome Measures}

At 3 and 12 months post-operatively, the same specialist physiotherapist re-measured knee flexion using a goniometer and assigning WOMAC and SF-12 scores. Both the patient and physiotherapist remained blinded to the slope of the tibial insert. Patients were informed of its value after the database was frozen after the one-year review. Two authors (JRF and CJ), also blinded to the randomisation groups, independently reviewed the standard lateral postoperative radiographs to measure the prosthetic posterior tibial slope. Radiographers were instructed to obtain as true a lateral image as possible. The tibial slope was measured digitally as the angle between the medial tibial plateau and the proximal tibial anatomical axis (a line connecting the mid point of the tibia at 5 and $15 \mathrm{~cm}$ below the joint line) on a lateral knee radiograph. Both authors measured each patient twice on different occasions giving a total of four measurements for each patient and a mean of these values was calculated. Larger tibias have a larger antero-posterior distance, hence there will be a larger posterior drop in height with a $4^{\circ}$ posterior tibial slope than with smaller tibias and thus potentially greater flexion achieved. Further analysis was undertaken to assess whether tibial size was a factor. Patients were also divided into two groups (small and large) by tibial implant size. The Profix arthroplasty comes in six tibial sizes, numbered 1 to 6 , of which size 1 is not of standard availability and rarely used. It was not used in any patient in this cohort. We compared range of movement in those with a 'small' tibial implants, sizes 2, 3 and 4, against those with a 'large' implants, sizes 5 and 6.

\section{Results}

Two hundred and fifty six patients were recruited to the trial; six withdrew before surgery, leaving 250 who were randomised to a $0^{\circ}$ or $4^{\circ}$ tibial slope. Nine patients were subsequently lost to follow-up, leaving 241 patients with outcome measures. Baseline characteristics, pre-operative movement and quality of life measures were similar in both groups (Table 1), with a slight female predominance. No parameter was statistically significant.

Table 1: Demographic and pre-operative data (BMI: Body mass index; WOMAC: Western Ontario and McMaster Universities Osteoarthritis Index).

\begin{tabular}{|c|c|c|}
\hline & \multicolumn{2}{|c|}{ Posterior Tibial Slope } \\
\hline & 0 Degree & 4 Degree \\
\hline Number & 117 & 124 \\
\hline Mean Age (years) & 62 & 61 \\
\hline Mean BMI & 29.8 & 30.0 \\
\hline Distribution (Right:Left) & $72: 45$ & $61: 63$ \\
\hline Pre-op extension to flexion (Range) in degrees & $4-102(97)$ & $7-100(93)$ \\
\hline Pre-op WOMAC scores (95\% CI, SD and median) & $\begin{array}{c}57.5 \\
(14.0,0.43-0.57,56)\end{array}$ & $\begin{array}{c}57.0 \\
(15.9,0.43-0.57,58)\end{array}$ \\
\hline Pre-op SF 12 Ph score (95\% CI, SD and median) & $\begin{array}{c}28 \\
(9.5,32-52,33)\end{array}$ & $\begin{array}{c}27 \\
(9.2,32-52,34)\end{array}$ \\
\hline Pre-op SF-12 M score (95\% CI, SD and median) & $\begin{array}{c}51 \\
(11.1,41-62,54)\end{array}$ & $\begin{array}{c}51 \\
(9.2,41-62,53)\end{array}$ \\
\hline
\end{tabular}

\section{Primary Outcomes}

There was no significant difference in range of movement or quality of life measures at any point between the $0^{\circ}$ and $4^{\circ}$ groups (Table 2). The range of movement decreased in both groups at three months before improving back to pre-operative levels at one year. Patient reported outcomes improved significantly post-operatively. WOMAC scores also improved significantly with similar scores in both groups postoperatively. SF-12 scores likewise improved in both groups, with no significant difference between the two groups. There was no difference in the post-operative scores of any measure when comparing the 'small' and 'large' tibial sizes. The WOMAC scores were significantly higher pre-operatively for the 4 degree group with a greater improvement at 12 months but no significant difference in scores at 12 months compared to the 0 degree group. 
Table 2: Pre-op, 3 and 12 month results for each slope (WOMAC: Western Ontario and McMaster Universities Osteoarthritis Index; SF-12 Ph: Short Form-12 Physical score; Short Form-12 M: SF-12 Mental score).

\begin{tabular}{|c|c|c|c|c|}
\hline & & \multicolumn{2}{|c|}{ Posterior Tibial slope } & \multirow{2}{*}{ p-value } \\
\hline & & 0 Degree & 4 Degree & \\
\hline \multirow{3}{*}{ Range of Movement - degrees (Range) } & Pre-op & $4-102(97)$ & $7-100(93)$ & 0.11 \\
\hline & 3 months & $3-95(92)$ & $3-96(93)$ & 0.51 \\
\hline & 12 months & $1-98(97)$ & $1-98(97)$ & 0.72 \\
\hline \multirow{3}{*}{ WOMAC score (SD, 95\% CI, Median) } & Pre-op & $\begin{array}{c}57.5 \\
(14,43-58,56) \\
\end{array}$ & $\begin{array}{c}57.0 \\
(15.9,43-57,58)\end{array}$ & 0.89 \\
\hline & 3 months & $\begin{array}{c}33.3 \\
(17.8,45-65,34)\end{array}$ & $\begin{array}{c}34.5 \\
(18.5,45-65,40)\end{array}$ & 0.30 \\
\hline & 12 months & $\begin{array}{c}33.5 \\
(20.8,42-57,34)\end{array}$ & $\begin{array}{c}34.0 \\
(19.7,43-57,32)\end{array}$ & 0.99 \\
\hline Change in WOMAC at 12 months & & -24.1 & -24.0 & \\
\hline \multirow{2}{*}{ SF-12 Ph score (SD, 95\% CI, Median) } & Pre-op & $\begin{array}{c}28 \\
(9.5,32-52,33) \\
\end{array}$ & $\begin{array}{c}27 \\
(9.2,32-52,34) \\
\end{array}$ & 0.58 \\
\hline & 12 months & $\begin{array}{c}35 \\
(10.1,44-59,33) \\
\end{array}$ & $\begin{array}{c}33 \\
(10.4,44-59,33) \\
\end{array}$ & 0.75 \\
\hline Change in SF-12 Ph & & 7 & 6 & \\
\hline \multirow{2}{*}{ SF-12 M score (SD, 95\% CI, Median) } & Pre-op & $\begin{array}{c}51 \\
(11.1,41-62,54)\end{array}$ & $\begin{array}{c}51 \\
(9.2,41-62,53) \\
\end{array}$ & 0.68 \\
\hline & 12 months & $\begin{array}{c}51 \\
(9.5,46-60,53) \\
\end{array}$ & $\begin{array}{c}55 \\
(9.5,46-60,33) \\
\end{array}$ & 0.34 \\
\hline Change in SF-12 M & & 0 & 4 & \\
\hline
\end{tabular}

\section{Secondary Outcomes}

On measurement of the lateral $x$-rays, the mean tibial slope in the $0^{\circ}$ group was $0.4^{\circ}\left(-1.1^{\circ}\right.$ to $\left.3.9^{\circ}\right)$ and $2.2^{\circ}$ in the $4^{\circ}$ group $\left(-0.6^{\circ}-\right.$ $\left.5.1^{\circ}\right)$. Intra-observer disparity between surgeons was minimal with a mean posterior slope of $0.5^{\circ}$ and $0.2^{\circ}$ in the $0^{\circ}$ group and $2.1^{\circ}$ and $2.4^{\circ}$ in the $4^{\circ}$ group. Moderate inter-observer correlation was seen between the two authors interpreting radiological posterior slope with a kappa value of 0.43 . There were no significant differences in range of movement within the small or large tibia subgroups $\left(0^{\circ}\right.$ : $\mathrm{p}=0.89 ; 4^{\circ}: \mathrm{p}=0.66$; (Tables $\left.3 \& 4\right)$ ). Demographics were similar in both groups with BMI in the small group being 30 and in the large group being 29 .

Table 3: Pre-op and 12 month results for each slope - 'small' tibias sizes 2,3 \& 4 (WOMAC: Western Ontario and McMaster Universities Osteoarthritis Index; SF-12 Ph: Short Form-12 Physical score; Short Form-12 M: SF-12 Mental score).

\begin{tabular}{|c|c|c|c|c|}
\hline & & \multicolumn{2}{|c|}{ Posterior Tibial Slope } & \multirow{2}{*}{ p-value } \\
\hline & & 0 Degree & 4 Degree & \\
\hline \multirow{3}{*}{$\begin{array}{l}\text { Range of movement - } \\
\text { degrees (range) }\end{array}$} & Pre-op & $4-100(96)$ & $7-101(94)$ & 0.40 \\
\hline & 3 months & 3-91 (88) & 3-96 (93) & 0.82 \\
\hline & 12 months & $1-98(97)$ & $1-98(97)$ & 0.89 \\
\hline \multirow{3}{*}{ WOMAC score } & Pre-op & 58 & 57 & 0.50 \\
\hline & 12 months & 34 & 32 & 0.84 \\
\hline & Change in score & -24 & -25 & \\
\hline \multirow{3}{*}{ SF-12 Ph score } & Pre-op & 27 & 27 & 0.99 \\
\hline & 12 months & 33 & 33 & 0.88 \\
\hline & Change in score & 6 & 6 & \\
\hline \multirow{3}{*}{ SF-12 M score } & Pre-op & 51 & 51 & 0.77 \\
\hline & 12 months & 53 & 55 & 0.55 \\
\hline & Change in score & 2 & 4 & \\
\hline
\end{tabular}


Table 4: Pre-op and 12 month results for each slope - 'large' tibias sizes 5 \& 6 (WOMAC: Western Ontario and McMaster Universities Osteoarthritis Index; SF-12 Ph: Short Form-12 Physical score; Short Form-12 M: SF-12 Mental score).

\begin{tabular}{|c|c|c|c|c|}
\hline & & \multicolumn{2}{|c|}{ Posterior Tibial Slope } & \multirow{2}{*}{ p-value } \\
\hline & & 0 Degree & 4 Degree & \\
\hline \multirow{3}{*}{$\begin{array}{l}\text { Range of movement - } \\
\text { degrees (range) }\end{array}$} & Pre-op & $3-108(105)$ & 9-98 (89) & 0.06 \\
\hline & 3 months & 4-97 (93) & 3-98 (95) & 0.74 \\
\hline & 12 months & $0-100(100)$ & $1-100(99)$ & 0.66 \\
\hline \multirow{3}{*}{ WOMAC score } & Pre-op & 49 & 59 & 0.03 \\
\hline & 12 months & 25 & 32 & 0.59 \\
\hline & Change in score & -24 & -27 & \\
\hline \multirow{3}{*}{ SF-12 Ph score } & Pre-op & 33 & 27 & 0.06 \\
\hline & 12 months & 32 & 34 & 0.66 \\
\hline & Change in score & 1 & 7 & \\
\hline \multirow{3}{*}{ SF-12 M score } & Pre-op & 49 & 51 & 0.66 \\
\hline & 12 months & 52 & 54 & 0.54 \\
\hline & Change in score & 3 & 3 & \\
\hline
\end{tabular}

\section{Discussion}

This randomised controlled double-blinded study shows no significant difference in either range of movement or patient reported outcome measures between the $0^{\circ}$ and $4^{\circ}$ groups at three and twelve months. The posterior tibial plateau slope plays an important role in the biomechanics of the knee joint by facilitating femoral roll-back, which differs between medial and lateral sides, and by maintaining tension on the posterior cruciate ligament [15]. Although debate persists, cruciate-retaining implants do not demonstrate normal knee kinematics but maintain some degree of femoral roll-back due to the tension retained on the posterior cruciate ligament. This suggests that a posterior tibial slope should widen the flexion gap and thus maximise flexion in cruciateretaining implants. Posterior stabilised knees show different knee kinematics where femoral roll-back is prevented by a cam and peg mechanism. In vitro studies have shown that an increased posterior tibial slope improves postoperative flexion and therefore flexion. The cadaveric study by Bellemans et al. showed significant improvement in maximal flexion $\left(104^{\circ}\right.$ to $\left.112^{\circ}\right)$ after increasing the tibial slope from $0^{\circ}$ to $4^{\circ}$. This group also showed that in a cruciateretaining knee, impingement of the back of the femur on the tibial baseplate was the primary block on further flexion [16]. Yet to date these improvements in flexion have not been replicated in clinical studies nor related to improved patient-reported outcomes [17].

Seo et al retrospectively looked at 801 knees and reported significantly better Kujala and Feller patella scores in patients with a tibial slope between $3^{\circ}$ and $-1^{\circ}$, but no significant improvement in movement [14]. Other retrospective clinical studies looking at both cruciate-retaining and posterior stabilised knee implants have failed to show a difference in either movement or patient outcome [9-13]. Our results fail to show improved flexion or patient outcome with increasing the posterior tibial slope. To better understand this result, we measured the tibial slope on lateral knee x-rays as post-operative CT scans were not part of the ethical request. No consensus on radiological measurement of posterior tibial slope has been established and there are inherent inaccuracies in each method used of approximately 3 to 4 degrees [18]. Proximal tibial anatomical axis has been shown to correlate accurately with the tibial mechanical axis and hence this measurement technique was used [19]. Although there would have been an element of rotational inaccuracy in some films, the same form of x-ray was used in the entire series. Accuracy of the method was suggested by the fact that the $0^{\circ}$ group averaged $0.2^{\circ}$ on $x$-ray, confirming that cutting a $0^{\circ}$ slope indeed gives that angle. However, cutting a $4^{\circ}$ slope gave an average of $2.2^{\circ}$ radiographically. Both surgeons obtained similar results with a mean tibial slope of 2.4 and 2.1 radiographically indicating it was not a single surgeon technical error that led to a lower tibial slope than expected with the cutting jig. The differences between intra-operative and radiographically measured tibial slope may be explained by subtle inaccuracies in placing the jig on the anterior tibia; any internal or external rotation would lead to a $4^{\circ}$ slope but not in the true sagittal plane, resulting in a reduced slope. Inaccuracies in radiographical measurement of slope will also occur with variation depending on what technique is used. According to the cadaveric work by Bellemans even with an increase of $2^{\circ}$ tibial slope we would still expect to see an additional $3.5^{\circ}$ to $4^{\circ}$ of flexion. This was not mirrored in our results. Despite possible inaccuracies in radiographic measurement the slope obtained, when using this surgical technique no difference in postoperative range of movement and patient reported outcomes are seen. Ismalilidis published work to suggest that differences in the posterior tibial slope should not contribute to a rotational malalignment if the anatomical tibial axis was used to align an arthroplasty [20]. 
Cutting the tibial slope parallel to the physiological preoperative slope rather than to a pre-determined angle has been suggested to result in better soft tissue balancing and more 'normal' knee kinematics. As this study was designed to look for a difference in post-operative range of movement and outcomes scores using a widely accepted technique used by many surgeons of pre-operatively planned tibial slope of $4^{\circ}$ or $0^{\circ}$, the better softtissue balancing in a $0^{\circ}$ knee may explain why we see no difference in flexion or patient-related outcome between the two groups. Comparison of small and large tibias also failed to yield any difference in movement. A posterior tibial slope in a larger tibia will cause a bigger drop in posterior tibial height than in a small tibia, hence delaying contact between posterior tibia and femur during deep flexion. Theoretically this should lead to increased flexion. However, we failed to reveal a significant difference in flexion between subgroups with similar body mass index. This may be explained by Nagamine's work who showed that in 208 patients undergoing total knee replacement, the proximal tibial condyle did not have a posterior slope in $86.5 \%$ of patients [21]. There showed that the posterior slope occurs in the proximal metaphysis of the tibia and that the tibial condyle rotates posteriorly. Hence the posterior tibial slope is mainly created by the poser rotation of the tibial condyle.

Our results should be extrapolated to other knee replacement designs with caution. Posterior stabilised designs show different kinematics from cruciate-retaining implants, while subtle differences in design in both cruciate-retaining and cruciate-sparing implants may also affect femoro-tibial component congruity, influencing kinematics with a suggested optimal posterior tibial slope ranging from $0^{\circ}$ to $10^{\circ}[22,23]$. However, the relatively deep dish design of the Profix prosthesis used in this study is probably more prone to impingement than less conforming knees. More modern designs may negate these issues, in particular if they are intended to achieve more normal kinematics. Hence, as in all trials, each implant should be assessed individually. It should also be noted that this study is limited to a single site and patient population. The vast majority of our patients are White British; other tibial slope values are seen in different populations and ethnic groups [24]. Given that the influence of the posterior tibial slope can only be demonstrated in a cadaveric setting, in vivo studies have failed to demonstrate a correlation and therefore the clinical significance of the tibial slope within a narrow therapeutic window may be negligible.

\section{Acknowledgement}

The authors would like to thank the University of Liverpool, Department of Statistics, for their help in statistical analysis and setting up the trial.

\section{References}

1. Kiebzak GM, Pierson LM, Campbell M, Cook JW (2002) Use of the SF36 general health status survey to document health-related quality of life in patients with coronary artery disease: effect of disease and response to coronary artery bypass graft surgery. Heart Lung J Crit Care 31(3): 207-213.

2. Carr AJ, Robertson O, Graves S, Price AJ, Arden NK, et al. (2012) Knee replacement. Lancet 379(9823): 1331-1340.

3. Ritter MA, Berend ME, Harty LD, Davis KE, Meding JB, et al. (2004) Predicting range of motion after revision total knee arthroplasty: clustering and log-linear regression analyses. J Arthroplasty 19(3): 338343 .

4. Miner AL, Lingard EA, Wright EA, Sledge CB, Katz JN, et al. (2003) Knee range of motion after total knee arthroplasty: how important is this as an outcome measure? J Arthroplasty 18(3): 286-294.

5. Laubenthal KN, Smidt GL, Kettelkamp DB (1972) A quantitative analysis of knee motion during activities of daily living. Phys Ther 52(1): 34-43.

6. Kotani A, Yonekura A, Bourne RB (2005) Factors influencing range of motion after contemporary total knee arthroplasty. J Arthroplasty 20(7): 850-856.

7. Gatha NM, Clarke HD, Fuchs R, Scuderi GR, Insall JN (2004) Factors affecting postoperative range of motion after total knee arthroplasty. J Knee Surg 17(4): 196-202.

8. Kim YH, Park JW, Kim JS, Park SD (2014) The relationship between the survival of total knee arthroplasty and postoperative coronal, sagittal and rotational alignment of knee prosthesis. Int Orthop 38(2): 379-385.

9. Bellemans J, Robijns F, Duerinckx J, Banks S, Vandenneucker H (2005) The influence of tibial slope on maximal flexion after total knee arthroplasty. Knee Surg Sports Traumatol Arthrosc 13(3): 193-196.

10. Walker PS, Garg A (1991) Range of motion in total knee arthroplasty. A computer analysis. Clin Orthop 262: 227-235.

11. Kansara D, Markel DC (2006) The effect of posterior tibial slope on range of motion after total knee arthroplasty. J Arthroplasty 21(6): 809-813.

12. Bauer T, Biau D, Colmar M, Poux X, Hardy P, et al. (2010) Influence of posterior condylar offset on knee flexion after cruciate-sacrificing mobile-bearing total knee replacement: a prospective analysis of 410 consecutive cases. Knee 17(6): 375-380.

13. Malviya A, Lingard EA, Weir DJ, Deehan DJ (290) Predicting range of movement after knee replacement: the importance of posterior condylar offset and tibial slope. Knee Surg Sports Traumatol Arthrosc 17(5): 491498.

14. Seo SS, Kim CW, Kim JH, Min YK (2013) Clinical results associated with changes of posterior tibial slope in total knee arthroplasty. Knee Surg Relat Res 25(1): 25-29.

15. Aigner C, Windhager R, Pechmann M, Rehak P, Engeleke K (2004) The influence of an anterior-posterior gliding mobile bearing on range of motion after total knee arthroplasty. A prospective, randomized, doubleblinded study. J Bone Joint Surg (Am) 86(10): 2257-2262.

16. Bellemans J, Banks S, Victor J, Vandenneucker H, Moemans A (2002) Fluoroscopic analysis of the kinematics of deep flexion in total knee arthroplasty. Influence of posterior condylar offset. J Bone Joint Surg (Br) 84(1): 50-53

17. Kim KH, Bin SI, Kim JM (2012) The Correlation between Posterior tibial slope and Maximal Angle of Flexion after Total Knee Arthroplasty. Knee Surg Relat Res 24(3): 158-163.

18. Brazier J, Migaud H, Gougeon F, Cotten A, Fontaine C, et al. (1996) Evaluation of methods for radiographic measurement of the tibial slope. 
A study of 83 healthy knees. Rev Chir Orthop Reparatrice Appar Mot 82(3): 195-200.

19. Yoo JH, Chang CB, Shin KS, Seong SC, Kim TK (2008) Anatomical landmarks to assess the posterior tibial slope in total knee arthroplasty: a comparison of 5 anatomical axes. J Arthroplasty 23(4): 586-592.

20. Ismailidis P, Kremo V, Mündermann A, Müller Gerbl M, Nowakowski AM (2020) Total knee arthroplasty: posterior tibial slope influences the size but not the rotational alignment of the tibial component. Knee Surg Sports Traumatol Arthrosc 28(12): 3899-3905.

21. Nagamine R, Kawasaki M, Kim KI, Sakai A, Suguro T (2020) The posterior tibial slope is mainly created by the posterior rotation of the tibial condyles. J Orthop Surg 28(3): 2309499020975580.

ISSN: 2574-1241

DOI: 10.26717/BJSTR.2021.35.005719

AJA Santini. Biomed J Sci \& Tech Res

(C) (P) This work is licensed under Creative

Submission Link: https://biomedres.us/submit-manuscript.php
22. Whiteside LA, Amador DD (1988) The effect of posterior tibial slope on knee stability after Ortholoc total knee arthroplasty. J Arthroplasty 3: S51-57.

23. Dorr LD, Boiardo RA (1986) Technical considerations in total knee arthroplasty. Clin Orthop 205: 5-11.

24. De Boer JJ, Blankevoort L, Kingma I, Vorster W (2009) In vitro study of inter-individual variation in posterior slope in the knee joint. Clin Biomech 24(6): 488-492.

$\begin{array}{ll}\text { BIOMEDICAL } & \text { Assets of Publishing with us } \\ \text { RESEARCHES } & \text { - Global archiving of articles } \\ \text { - Immediate, unrestricted online access }\end{array}$

